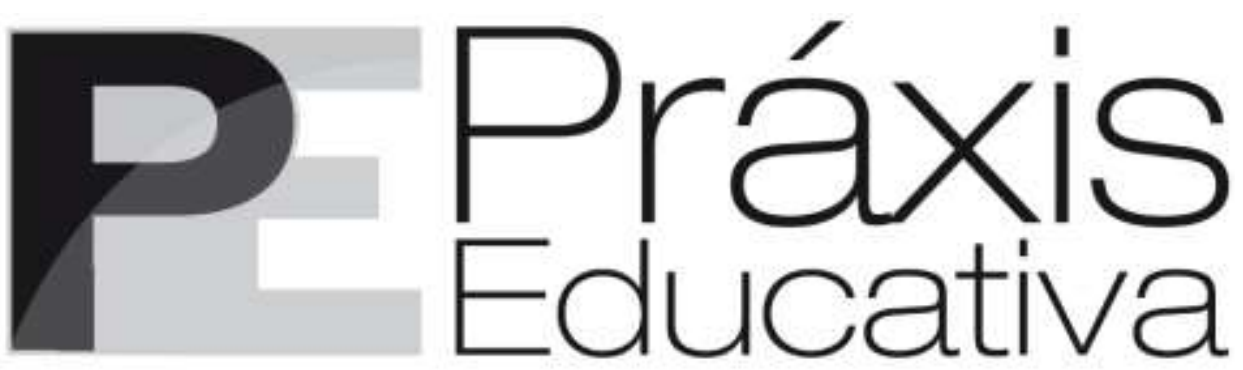

ISSN 1809-4031

elSSN 1809-4309

https://doi.org/10.5212/PraxEduc.v.16.19600.078

Seção: Artigos

\title{
Estrutura das representações sociais das regras escolares*
}

Structure of social representations of school rules

\section{Estructura de las representaciones sociales de las reglas escolares}

\author{
Viviane Terezinha Koga* \\ iD https://orcid.org/0000-0003-0726-3906 \\ Ademir José Rosso ${ }^{* * *}$ \\ iD http://orcid.org/0000-0002-7143-0433
}

\begin{abstract}
Resumo: Neste texto, foi investigada a estrutura das representações sociais de alunos do $9^{\circ}$ ano do Ensino Fundamental acerca das regras escolares. O referencial teórico é a abordagem estrutural das representações sociais (ABRIC, 1994) e a Teoria do Desenvolvimento Moral (PIAGET, 1994). A coleta dos dados foi realizada mediante a aplicação de questionário para 359 alunos. A análise dos dados foi feita com o auxílio dos softwares SPSS, Evoc, Simi e com a análise de conteúdo. Os resultados indicaram uma representação social estruturada a partir do "celular e uniforme" e "respeito". Há uma ambivalência acerca desses objetos: de um lado, estão os aspectos normativos; e, de outro, os funcionais. Diante do valor que possui caráter normativo, têm-se o consenso da sua necessidade para o bom convívio escolar. Assim sendo, destaca-se a importância de as escolas construírem iniciativas para a educação moral dos alunos para não ficarem sujeitos a políticas neoconservadoras fundamentadas na heteronomia moral.
\end{abstract}

Palavras-chave: Educação moral. Alunos. Escolas públicas.

Abstract: In this text, the structure of the social representations of students from the 9th grade of Elementary School about school rules was investigated. The theoretical framework is the structural approach to social representations (ABRIC, 1994) and the Moral Development Theory (PIAGET, 1994). Data collection was carried out through a questionnaire applied to 359 students. Data analysis was performed using the SPSS, Evoc, Simi softwares and content analysis. The results indicate a social representation structured from the "cellphone and uniform", and "respect". There is ambivalence on the

\footnotetext{
* Esta pesquisa foi desenvolvida com o apoio financeiro concedido pela Coordenação de Aperfeiçoamento de Pessoal de Nível Superior (Capes).

** Doutora em Educação. Professora na Universidade Estadual de Ponta Grossa (UEPG). E-mail: <vivianekoga@gmail.com>.

*** Doutor em Educação. Professor no Programa de Pós-Graduação em Educação (PPGE) da Universidade Estadual de Ponta Grossa (UEPG). E-mail: <ajrosso@uepg.br>.
}

Práxis Educativa, Ponta Grossa, v. 16, e2119600, p. 1-19, 2021 Disponível em: <https://www.revistas2.uepg.br/index.php/praxiseducativa> 
objects: on the one hand, normative aspects are found; and, on the other hand, the functional aspects. Before the value that presents normative character, there is a consensus of their need for good school life. Thus, the importance of schools to build initiatives for the moral education of students so that they are not subject to neoconservative policies based on moral heteronomy is highlighted.

Keywords: Moral education. Students. Public schools.

Resumen: En este texto, fue investigada la estructura de las representaciones sociales de alumnos del noveno año de Enseñanza Primaria sobre las reglas escolares. El referencial teórico es el abordaje Estructural de las Representaciones Sociales (ABRIC, 1994) y la Teoría del Desarrollo Moral (PIAGET, 1994). La recolección de datos fue realizada por medio de aplicación de cuestionario para 359 alumnos. El análisis de datos fue hecho con el auxilio de los softwares SPSS, EVOC, SIMI y con el análisis de contenido. Los resultados indicaron una representación social estructurada a partir de lo "celular y uniforme", y "respeto". Hay ambivalencia delante de estos objetos: de un lado, están los aspectos normativos; y del otro, los funcionales. Delante del valor que posee carácter normativo, hay consenso de su necesidad para un buen convivio escolar. Así, se destaca la importancia de que las escuelas construyan iniciativas para la educación moral de los alumnos para que no queden sujetos a políticas neoconservadoras fundamentadas en la heteronomía moral.

Palabras clave: Educación moral. Alumnos. Escuelas públicas.

\section{Introdução}

A relação da educação moral com a escola não é algo novo. O primeiro projeto educacional, produzido em 1826, já trazia indícios de que os alunos deveriam ter conhecimentos morais e cívicos (LIMA, 2008). No período da ditadura militar (instalada pelo Golpe de 1964), a educação moral passou a fazer parte do ensino formal como uma disciplina obrigatória (SHIMIZU; CORDEIRO; MENIN, 2006), que visava a formar o "[...] cidadão obediente às normas e às autoridades, além de controlar a ordem social e promover a adequação às leis" (SHIMIZU et al., 2010, p. 2). "Tratavase de um decreto de obediência [...] para a promoção da ordem social vinculada aos ideais militares de controle e repressão da sociedade" (SHIMIZU; CORDEIRO; MENIN, 2006, p. 169). Depois de instalada a democracia, apenas com a promulgação da Lei $\mathrm{N}^{\circ}$ 8.663, de 14 de junho de 1993, a obrigatoriedade dessa disciplina foi revogada no currículo escolar (BRASIL, 1993). Passou, então, a predominar, nas escolas públicas, uma concepção relativista da educação moral, na qual as decisões relacionadas a ela seriam guiadas mais por parâmetros individuais do que coletivos (SHIMIZU; CORDEIRO; MENIN, 2006).

Mesmo não estando presente de forma expressa e planejada nas escolas, o tema continuou sendo proposto no âmbito político. No período de 1996 a 2006, foram apresentadas 13 propostas para a reintrodução de uma disciplina que contemplasse ética e cidadania, em busca do resgate de valores supostamente perdidos pela sociedade (AMARAL; CASTRO, 2020). Em 2018, o tema retornou à pauta com a criação da Subsecretaria de Fomento às Escolas Cívico-Militares, por meio do Decreto No 9.665, de 2 de janeiro de 2019 (BRASIL, 2019), período em que a agenda conservadora ganhou impulso, aliada ao discurso salvacionista que colocava, novamente, em tela, a disputa pela formação moral da juventude (AMARAL; CASTRO, 2020).

No âmbito acadêmico, a exemplo da constante presença na política, houve uma evolução significativa de pesquisas relacionadas à educação moral. La Taille, Souza e Viziolli (2004) apontam que, entre 1990 e 2003, ainda era reduzido o número de investigações sobre o tema, principalmente em análises empíricas, sendo desproporcional à preocupação e à demanda dos professores. Todavia, Koga e Rosso (2016) assinalam para o crescimento dessas publicações, especialmente das pesquisas empíricas, dentre as quais se destacam Menin (2002, 2007), Araújo (2000), Vinha (2000), Tardeli (2003) Shimizu, Cordeiro e Menin (2006) La Taille (2009), Trevisol (2009), Menin, Bataglia e Zechi (2013), Tognetta (2013), Santos e Trevisol (2016), Koga e Rosso (2020), dentre outros. 
No âmbito escolar, o tema é expresso pelo deterioramento das relações entre os agentes escolares, revelado pelas inúmeras queixas de professores diante dos conflitos, da falta de respeito, da ausência de limites, da violência (LOBATO; PLACCO, 2007; SILVA; CASTRO, 2008; PARRAT-DAYAN, 2009), da indisciplina (SANTOS; ROSSO, 2012) e do desinteresse pelas atividades escolares (ROSSO; CAMARGO, 2011; KOGA, 2012). Tais situações causam desgaste e sofrimento no trabalho docente (ROSSO; CAMARGO, 2011), provocam desequilíbrio e angústia (PARRAT-DAYAN, 2009) e geram um ambiente tenso, no qual "[...] professor e aluno já não se aguentam" mais (TOGNETTA; VINHA, 2007, p. 18). Nesse contexto, os professores dedicam entre $21 \%$ e $40 \%$ do seu tempo para a resolução de problemas morais (FANTE, 2003) e mais de 70\% afirmam que adotam atitudes autoritárias e impositivas (TARDELI, 2003).

O fato é que estamos diante de uma fragilização dos valores morais, os quais são, cada vez mais, plurais e instáveis. Vivemos uma crise de valores morais, éticos, humanísticos (BAUMAN, 1998; GEORGEN, 2001; JARES, 2005; LA TAILLE, 2009) ou então os valores estariam sendo reinterpretados, passando por um processo de transformação (LA TAILLE; MENIN, 2009). Nesse sentido, não é suficiente o estabelecimento de uma disciplina, a criação de escolas cívico-militares ou a ação docente punitiva e disciplinar. $\mathrm{O}$ fundamento para a educação moral está na cooperação, na solidariedade e no respeito mútuo, construídos socialmente e de forma ativa, bem como na relação existente entre a prática e a teoria, uma vez que a primeira não pode ser considerada decorrente da segunda. De tal modo, não basta falarmos aos alunos sobre moral ou convocá-los a seguir determinadas regras e normas, visto que o ensinamento verbal não é garantia para a ação moral. Ao contrário, a atividade é a base da moralidade, pois primeiro vem a ação, e, depois, a tomada de consciência (abstração das práticas) (PIAGET, 1994). Assim, o aluno precisa ser entendido como agente do processo moral, o qual, por meio das suas relações sociais, "[...] age primeiro para depois compreender que as regras contêm possibilidades de serem criadas e modificadas" (SOUZA; VASCONCELOS, 2009, p. 344). De tal modo, a educação moral tem como pressuposto básico a ação, a atividade cognitiva dos alunos diante das regras e das normas escolares (KOGA; ROSSO, 2016). Logo, o desenvolvimento moral constitui-se como um processo gradual dependente do cotidiano das escolas, na medida em que ele possa ser compreendido como uma produção democrática e coletiva, "[...] que contemple a multiplicidade de sujeitos e as condições adversas dos contextos nos quais estão inseridos" (AMARAL; CASTRO, 2020, p. 1092), assim como a compreensão dos sentidos e dos significados que fundamentam as regras.

Para Piaget (1994, p. 23), "[...] a moral consiste num sistema de regras, e a essência da moralidade deve ser procurada no respeito que o indivíduo adquire por essas regras". Dessa forma, o comportamento moral coloca, sempre, os indivíduos em ação. Agir moralmente exige a decisão livre e consciente, assumida por uma convicção interna e não por um processo exterior e impessoal (VÁSQUEZ, 2002). No que se refere à prática das regras, a sua codificação acontece em torno dos 11 aos 12 anos, em que as interações passam a ser regulamentadas nas suas particularidades e os pormenores das regras passam a ser conhecidos por todos. Nessa faixa etária, os sujeitos preveem todos os casos possíveis e os codificam. É, nesse momento, que "[...] a consciência da regra se transforma completamente" (PIAGET, 1994, p. 60). Agora, ela não mais se apresenta como algo exterior, mas como resultado de livre adesão. Torna-se digna de respeito, na medida em que é mutuamente construída. Assim "[...] todas as opiniões são permitidas, contanto que aqueles que a emitirem procurem fazer com que sejam aceitas pelas vias legais" (PIAGET, 1994, p. 60). A transformação das regras passa, então, pela aprovação da maioria dos envolvidos. Nessa perspectiva, entendemos a regra como uma decisão livre e consciente. De tal modo, "[...] não é coercitiva, nem exterior", mas "[...] é uma construção progressiva e autônoma” (PIAGET, 1994, p. 64).

Práxis Educativa, Ponta Grossa, v. 16, e2119600, p. 1-19, 2021

Disponível em: < https://www.revistas2.uepg.br/index.php/praxiseducativa> 
Desde o nascimento, até mesmo antes de aprender a falar, o ser humano está exposto a um sistema de regras e de normas. Ao entrar para a escola, vai se deparando com situações nas quais necessitam de regras e, assim, constroem e partilham, socialmente, percepções, manifestam atitudes e imagens acerca dessas regras, as quais circulam e passam a fazer parte da rotina escolar (JODELET, 2007; JOVCHELOVITCH, 1999). Os alunos, dessa forma, encontram-se imersos nas normas escolares; por vezes, agem de forma intuitiva diante delas, tomam por base a sua experiência e constroem representações sociais, as quais são teorias espontâneas, verdadeiras reconstruções que se tornam circulantes e partilhadas nas escolas.

Transitando entre esses elementos e nos detendo, principalmente, no último, delineamos o objetivo deste artigo que consiste em investigar a estrutura das representações sociais dos alunos do $9^{\circ}$ ano do Ensino Fundamental acerca das regras presentes em escolas estaduais da cidade de Ponta Grossa, no Paraná (PR). A fundamentação teórica está na dimensão estrutural das representações sociais de Abric (1994) e na Teoria do Desenvolvimento Moral de Piaget (1994). A justificativa reside no fato de que a identificação e a análise das representações sociais, elaboradas pelos alunos acerca das regras escolares, possibilitam a compreensão das relações estabelecidas nas escolas, no que se refere à educação moral, bem como auxiliam na edificação de caminhos para uma construção moral mais justa, democrática, pautada no respeito mútuo e em relações de cooperação, tendo em vista o desenvolvimento da autonomia moral e intelectual dos alunos, no sentido contrário ao que vem sendo proposto sobre o tema no atual contexto da política educacional brasileira. Para tanto, na sequência, explicitamos a dimensão estrutural das representações sociais. Em seguida, apresentamos os procedimentos metodológicos adotados na pesquisa, a análise e a discussão dos dados, e, por fim, as considerações finais.

\section{A dimensão estrutural das representações sociais}

As representações sociais constituem um conjunto de explicações, de conceitos e de afirmações presentes nas comunicações interpessoais, as quais são análogas aos mitos e às crenças das sociedades tradicionais. Estudá-las implica determo-nos na forma como o sujeito apreende e compreende os objetos que o circulam, e, ainda, como se dão esses esforços dos sujeitos ativos que pensam, produzem e comunicam representações (MOSCOVICI, 2012). "Representar uma coisa, não consiste simplesmente em desdobrá-la, repeti-la ou reproduzi-la; é reconstituí-la, retocá-la, modificar-lhe o texto" (MOSCOVICI, 2012, p. 54). Assim, “[...] representar é repensar, reexperimentar, refazer a nosso modo, em nosso contexto" (MOSCOVICI, 2012, p. 59).

Os alunos não são passivos ao reproduzirem as regras, mas as reconstroem, atribuindo a elas um sentido próprio, o que revela a função simbólica das representações. Elas circulam, se cruzam e se cristalizam por meio do diálogo, dos gestos e dos encontros cotidianos. Desse modo, grande parte das relações sociais, dos objetos que circulam e das distintas formas de comunicações que estabelecem é carregada de representações sociais (MOSCOVICI, 2012). Ao depararem-se com um objeto, como, por exemplo, as regras escolares, os sujeitos aproximam-no do seu universo, dos conhecimentos que possuem, e, assim, instituem uma linguagem particular assentada em valores e em conceitos (MOSCOVICI, 2012). Logo, as representações sociais das regras escolares não são apenas "opiniões sobre" ou "imagens de", mas são "[...] teorias coletivas destinadas à interpretação e elaboração do real" (MOSCOVICI, 2012, p. 47). Elas possuem, portanto, uma lógica e uma linguagem particular que "[...] determinam o campo das comunicações possíveis, dos valores ou das ideias presentes nas visões compartilhadas pelos grupos" (MOSCOVICI, 2012, p. 47).

A dimensão estrutural das representações sociais, proposta, em 1976, por Jean Claude Abric, igualmente denominada Teoria do Núcleo Central (TNC), sustenta que os elementos de

Práxis Educativa, Ponta Grossa, v. 16, e2119600, p. 1-19, 2021

Disponível em: <https://www.revistas2.uepg.br/index.php/praxiseducativa> 
uma representação social são hierarquizados e que toda representação social é organizada em torno de um núcleo central, composto por um ou mais elementos estáveis, resistentes à mudança. Cabe a esses elementos determinar o significado da representação (ABRIC, 2001; SÁ, 1996). Assim, “[...] procurar o núcleo central é procurar a raiz, o fundamento social da representação" (ABRIC, 2003, p. 40).

O núcleo central é associado à ideia de coletivo, a base comum propriamente social que define a homogeneidade de um grupo. Dessa forma, o núcleo central caracteriza-se como o elemento fundamental de uma representação social, visto que determina, ao mesmo tempo, o seu significado e a sua organização (ABRIC, 2005). Por ser compartilhado pelos sujeitos de um mesmo grupo, ele se caracteriza como um ponto de difícil alteração, pois concentra um valor comum atribuído pelos sujeitos a um determinado objeto. Logo, uma mudança brusca no núcleo central altera a homogeneidade do grupo. Entretanto, devemos ressaltar que o próprio núcleo central é hierarquizado, podendo compreender alguns elementos considerados mais importantes que outros (ABRIC, 2001).

O sistema periférico, que estabelece "[...] a interface entre a realidade concreta e o sistema central” (SÁ, 1996, p. 73), constitui a parte operante da representação; assim, tem sua importância relacionada ao funcionamento e à dinâmica das representações sociais. Ademais, caracteriza-se por

ser mais leve e flexível. É a parte mais viva e acessível da representação social (ABRIC, 2001). Funciona como um script que decodifica as situações, permitindo a representação funcionar de forma econômica, e serve como um "para-choque" entre a realidade em contínua mudança e o núcleo central que não pode mudar (FLAMENT, 2001).

\section{Percurso metodológico}

A pesquisa foi realizada mediante a aplicação de um questionário com 359 alunos do $9^{\circ}$ ano do Ensino Fundamental, em quatro escolas estaduais da cidade de Ponta Grossa (PR), identificadas pelas letras A, B, C e D. A opção pelo $9^{\circ}$ ano deu-se em virtude da faixa etária dos alunos. Já a escolha das escolas foi feita a partir de um estudo exploratório com 57 pedagogas que atuam em 36 das 50 escolas estaduais da referida cidade. A partir da aplicação desse questionário, verificamos que nas 36 escolas havia problemas morais e que nenhuma delas têm projetos e/ou iniciativas próprias desenvolvidas para prevenir ou combater esses problemas. Ao considerarmos a inexistência de iniciativas e levando em conta que, por vezes, as escolas de periferia são as mais desassistidas em pessoal e infraestrutura, o que pode influenciar negativamente na elaboração e na condução de ações morais, optamos por selecionar as escolas A, B e D que têm uma localização periférica, e a escola $\mathrm{C}$ que tem localização central, mas atende alunos nessas condições.

O questionário aplicado foi preparado com o objetivo de identificar as representações sociais dos alunos acerca das regras escolares; desse modo, utilizamos a técnica de associação livre de palavras (ABRIC, 1994). Para tanto, foi solicitado aos alunos que escrevessem cinco palavras ou expressões a partir de um termo indutor: "O que você pensa a respeito das regras da sua escola?". Após listar as palavras, eles deveriam enumerá-las segundo o grau de importância e justificar a expressão indicada em primeiro lugar. $O$ instrumento continha, ainda, questões referentes à caracterização dos alunos, tais como sexo, idade, religião, hábitos de estudo, autoavaliação, entre outras. A presente pesquisa teve a aprovação do Comitê de Ética, sob o Parecer N ${ }^{\circ}$ 1.064.148, e foram seguidos todos os procedimentos requeridos em pesquisas com seres humanos, dentre eles o consentimento dos alunos por escrito no Termo de Consentimento Livre e Esclarecido (TCLE), o resguardo das relações de poder abusivas e o anonimato (SPINK, 2000). Após a coleta, as informações foram organizadas em um banco de dados no Excelpara posterior análise.

Práxis Educativa, Ponta Grossa, v. 16, e2119600, p. 1-19, 2021 Disponível em: <https://www.revistas2.uepg.br/index.php/praxiseducativa> 
Os dados foram analisados adotando-se procedimentos quantitativos com o auxílio dos softwares SPSS (Statistical Package for Social Sciences for Windows), Evoc (Ensemble de programmespermettantl'analyse dês evocations), Complex e Simi, seguidos de procedimentos qualitativos de análise de conteúdo (BARDIN, 2004). O SPSS foi utilizado para a análise quantitativa das respostas nas questões de caracterização dos sujeitos investigados; o Evoc, para a identificação da estrutura da representação social, do provável núcleo central e sistema periférico, por meio de cálculos de coocorrências que servem de base para a construção dos quatro quadrantes (MACHADO; ANICETO, 2010); o Complex, para a análise de variáveis significativas dentre os diferentes subgrupos de alunos investigados; e o Simi, para a análise da conexão entre os diversos elementos representacionais (SÁ, 1996). Por fim, realizamos a análise de conteúdo para elencar as categorias presentes nas justificativas dos alunos à palavra indicada em primeiro lugar na questão de associação livre de palavras (BARDIN, 2004).

\section{Resultados e discussão}

Para a caracterização dos alunos participantes, estão descritas, na Tabela 1, as seguintes variáveis: número de alunos por escola, gênero, idade, se possui crença religiosa, religião, moradia, se possui irmãos, reprovação, hábitos de estudo, autoavaliação e conduta escolar.

Tabela 1 - Caracterização dos sujeitos participantes

\begin{tabular}{|c|c|c|c|}
\hline \multicolumn{2}{|l|}{ Variáveis } & Quantidade & Percentagem \\
\hline \multirow{4}{*}{ Alunos } & Escola A & 53 & $14,76 \%$ \\
\hline & Escola B & 170 & $47,35 \%$ \\
\hline & Escola C & 36 & $10,02 \%$ \\
\hline & Escola D & 100 & $27,85 \%$ \\
\hline \multirow{2}{*}{ Gênero } & Masculino & 165 & $45,96 \%$ \\
\hline & Feminino & 194 & $54,03 \%$ \\
\hline \multirow{3}{*}{ Faixa etária } & 14 a 15 anos & 308 & $85,79 \%$ \\
\hline & 15 a 17 anos & 40 & $11,14 \%$ \\
\hline & Acima de 17 anos & 5 & $1,39 \%$ \\
\hline \multirow{3}{*}{ Crença religiosa } & $\operatorname{Sim}$ & 289 & $80,50 \%$ \\
\hline & Não & 70 & $19,49 \%$ \\
\hline & Não respondeu & 77 & $21,44 \%$ \\
\hline \multirow{4}{*}{ Religião } & Católica & 168 & $46,79 \%$ \\
\hline & Evangélica & 101 & $28,13 \%$ \\
\hline & Espírita & 5 & $1,39 \%$ \\
\hline & Outra & 8 & $2,22 \%$ \\
\hline \multirow{4}{*}{ Mora com quem } & Pai e mãe & 222 & $61,83 \%$ \\
\hline & Somente pai ou mãe & 75 & $20,89 \%$ \\
\hline & Mãe e padrasto & 47 & $13,09 \%$ \\
\hline & Outros & 15 & $4,17 \%$ \\
\hline \multirow{2}{*}{ Irmãos } & Sim & 327 & $91,08 \%$ \\
\hline & Não & 32 & $8,91 \%$ \\
\hline \multirow{2}{*}{ Reprovação } & Sim & 66 & $18,38 \%$ \\
\hline & Não & 293 & $81,61 \%$ \\
\hline \multirow{3}{*}{ Estuda em casa } & Sim & 115 & $32,03 \%$ \\
\hline & Não & 244 & $67,96 \%$ \\
\hline & Não estuda & 244 & $67,96 \%$ \\
\hline \multirow{4}{*}{ Horas diárias de estudo em casa } & 1 hora & 72 & $20,05 \%$ \\
\hline & 2 horas & 32 & $8,91 \%$ \\
\hline & 3 horas & 8 & $2,22 \%$ \\
\hline & +3 horas & 3 & $0,83 \%$ \\
\hline \multirow{3}{*}{ Autoavaliação do aluno } & Muito bom & 54 & $15,04 \%$ \\
\hline & Bom & 170 & $47,35 \%$ \\
\hline & Razoável & 120 & $33,42 \%$ \\
\hline
\end{tabular}

Práxis Educativa, Ponta Grossa, v. 16, e2119600, p. 1-19, 2021 Disponível em: <https://www.revistas2.uepg.br/index.php/praxiseducativa> 


\begin{tabular}{l|c|c|c}
\hline \multicolumn{2}{l|}{} & Quantidade & Percentagem \\
\hline \multirow{2}{*}{ Já brigou na escola } & Ruim & 15 & $4,17 \%$ \\
\hline \multirow{2}{*}{ Já foi encaminhado pedagoga } & Sim & 109 & $30,36 \%$ \\
\cline { 2 - 4 } & Não & 250 & $69,63 \%$ \\
\cline { 2 - 4 } & Sim & 220 & $61,28 \%$ \\
\hline
\end{tabular}

Fonte: Elaborada pelos autores, 2021.

Levando-se em consideração as variáveis utilizadas na caracterização dos alunos, fizemos um agrupamento para análise com o auxílio do software Complex. Para tanto, foram constituídas três variáveis: 1) fatores de vulnerabilidade social; 2) fatores que comprometem a escolarização; e 3) fatores que afetam a conduta escolar. $\mathrm{Na}$ primeira, levamos em conta a definição de vulnerabilidade de Janczura (2012), que se aplica a indivíduos que vivem em famílias pobres, com baixo nível socioeconômico, baixa remuneração parental, baixa escolaridade, em famílias numerosas e que têm a ausência de um dos pais. Desse modo, o aluno que tem família monoparental apresenta um fator de vulnerabilidade social, e aquele que possui essa condição aliada ao número de irmãos maior que cinco tem dois fatores.

Já para a composição da variável "fatores que comprometem a escolarização", consideramos três condições (reprovação, hábito de estudo e autoavaliação). Os alunos que já reprovaram têm um fator de comprometimento; os que já reprovaram e não estudam têm dois fatores; e aqueles que já reprovaram, não estudam e têm uma autoavaliação negativa possuem três fatores de comprometimento da escolarização. Por fim, no que se refere à variável "fatores que afetam a conduta escolar", levamos em conta duas condições: o aluno ter se envolvido em uma briga na escola e ter sido encaminhado para a sala da pedagoga. Da mesma forma, os alunos que já brigaram possuem um fator que afeta a sua conduta escolar e os que já brigaram e já foram encaminhados para a pedagoga possuem dois fatores. Nos três casos, durante o agrupamento, houve alunos em que esses fatores foram ausentes. Na Tabela 2, apresentamos a frequência e a percentagem de alunos em cada um dos fatores.

Tabela 2 - Análise das variáveis compostas

\begin{tabular}{l|c|c|c}
\hline Variáveis & Fatores & Quantidade & Percentagem \\
\hline \multirow{3}{*}{ Fatores de vulnerabilidade social } & Ausente & 252 & $70,19 \%$ \\
\cline { 2 - 4 } & Um (monoparental) & 95 & $26,46 \%$ \\
\cline { 2 - 4 } & Dois (+ cinco filhos) & 12 & $3,34 \%$ \\
\hline \multirow{3}{*}{$\begin{array}{l}\text { Fatores que comprometem a } \\
\text { escolarização }\end{array}$} & Ausente & 76 & $21,16 \%$ \\
\cline { 2 - 4 } & Um (reprovação) & 146 & $40,66 \%$ \\
\cline { 2 - 4 } & Dois (hábito estudo) & 111 & $30,91 \%$ \\
\cline { 2 - 4 } & Três (autoavaliação) & 26 & $7,24 \%$ \\
\hline \multirow{3}{*}{ Fatores que afetam a conduta escolar } & Ausente & 125 & $34,81 \%$ \\
\cline { 2 - 4 } & Um (brigas) & 139 & $38,71 \%$ \\
\cline { 2 - 4 } & Dois (encaminhado pedagoga) & 95 & $26,46 \%$ \\
\hline
\end{tabular}

Fonte: Elaborada pelos autores, 2021.

A análise da Tabela 2 evidencia que 70\% dos alunos investigados não possuem fatores de vulnerabilidade social. Esse dado faz um alerta, pois as políticas educacionais e a sociedade como um todo, ao tratarem dos problemas morais na escola (indisciplina, desinteresse e desrespeito), tendem a culpabilizar as famílias, apontando para a sua falência (RIBEIRO; RUBINI, 2019), a qual estaria relacionada, principalmente, à sua desestrutura e vulnerabilidade. Considerando que as quatro escolas investigadas têm localização periférica ou atendem alunos nessa condição, apenas $26,46 \%$ deles possuem um fator de vulnerabilidade, que é a situação familiar monoparental, e somente 3,34\% dos alunos têm dois fatores de vulnerabilidade social (família monoparental e mais que cinco irmãos).

Práxis Educativa, Ponta Grossa, v. 16, e2119600, p. 1-19, 2021 
Em relação aos fatores de comprometimento da escolarização, em 21,16\% dos alunos eles são ausentes. Além disso, aproximadamente, $40 \%$ dos alunos possuem um fator de comprometimento da escolarização que é a reprovação. Ao mesmo tempo, 30,91\% dos alunos têm dois fatores de comprometimento da escolarização, pois já reprovaram e não têm hábitos de estudo. Por fim, 7,24\% dos alunos têm três fatores que comprometem a sua escolarização, visto que já reprovaram, não têm hábitos de estudo e possuem uma autoavaliação negativa. No que se refere aos fatores que afetam a conduta escolar, em 34,81\% dos casos, eles são ausentes. Em $38,71 \%$ dos alunos, há um fator que afeta a conduta que é ter se envolvido em brigas na escola. Em $26,46 \%$ dos alunos, há dois fatores, pois já brigaram na escola e já foram encaminhados para a sala da pedagoga.

Analisando a Tabela 2 como um todo, dos três fatores que podem influenciar o processo de ensino e de aprendizagem e o desenvolvimento moral, a vulnerabilidade social é a que exerce menor influência. Podemos dizer que as questões relacionadas à moralidade nas quatro escolas investigadas são mais influenciadas pelo comprometimento dos alunos com a escolarização, em especial pela sua reprovação e por sua conduta escolar, como envolvimento em brigas, do que por sua vulnerabilidade social. Fato que, por vezes, é negligenciado tanto pelas políticas educacionais vigentes quanto pelo discurso social, os quais tendem a responsabilizar a situação familiar e a localização periférica das escolas (RIBEIRO; RUBINI, 2019).

As palavras ou expressões que foram evocadas pelos alunos, na primeira questão do questionário, a partir do termo indutor: "O que você pensa a respeito das regras da sua escola?", foram analisadas com o apoio do software Evoc. Para tanto, as palavras que tinham o mesmo valor semântico foram agrupadas. Após o tratamento e o processamento pelo software, verificamos que, do total de 359 informantes, se obteve uma lista com 1543 palavras, das quais 63 eram diferentes.

Para a composição dos quatro quadrantes, foram desprezadas as evocações cuja frequência mínima foi igual ou inferior a seis $(25 \%$ do total). Além disso, foi considerada a frequência intermediária 70 e a Ordem Média de Evocação (OME) 2,7, uma vez que esses valores foram extraídos do relatório RANGMOT. A frequência mínima é responsável por definir que apenas as palavras com seis ou mais evocações sejam apontadas e a frequência intermediária determina que somente as palavras com frequência acima de 70 entrem na composição dos quadrantes superiores. A OME, por sua vez, determina como as evocações serão posicionadas em relação ao eixo vertical (PAREDES, 2007).

Do total de 63 palavras diferentes evocadas pelos alunos, 18 integraram os quatro quadrantes, nos quais estão os possíveis elementos que compõem o núcleo central e o sistema periférico da representação social das regras. Esses elementos foram extraídos do relatório TABRGFR e são apresentados, na Tabela 3, seguidos das suas frequências e da OME.

Tabela 3 - Possíveis elementos que compõem o núcleo central e o sistema periférico das representações sociais das

\begin{tabular}{l|c|c|c|c|c}
\hline & Freq. & OME & & Freq. & OME \\
\hline Palavras & $>=70$ & $<2,7$ & Palavras & $>=70$ & $>=2,7$ \\
\hline Celular & 198 & 2,29 & Boné & 123 & 2,74 \\
\hline Respeito & 122 & 2,55 & Proibição & 163 & 2,92 \\
\hline Uniforme & 178 & 2,22 & & & \\
\hline Palavras & $<\mathbf{7 0}$ & $<\mathbf{2 , 7}$ & Palavras & $<\mathbf{7 0}$ & $>=2,7$ \\
\hline Boas & 39 & 2,61 & Chatas & 46 & 2,73 \\
\hline Desnecessárias & 50 & 2,50 & Cuidado escola & 33 & 3,33 \\
\hline Desrespeito & 19 & 2,31 & Fone ouvido & 59 & 3,42 \\
\hline Importantes & 38 & 2,28 & Horário & 65 & 3,30 \\
\hline Necessárias & 18 & 2,22 & Permanecer sala & 19 & 3,60 \\
\hline
\end{tabular}




\begin{tabular}{l|c|c|c|c|c}
\hline & Freq. & OME & & Freq. & OME \\
\hline Ruins & 37 & 2,59 & Sem sentido & 31 & 2,93 \\
\hline Rígidas & 23 & 1,87 & & & \\
\hline
\end{tabular}

Fonte: Elaborada pelos autores, 2021.

No primeiro quadrante, entre as palavras que possivelmente constituem o núcleo central, estão "celular", "uniforme" e "respeito". As palavras "celular" e "uniforme" caracterizam-se como aspectos funcionais das regras escolares. Juntas foram evocadas 376 vezes, o que indica uma forte tendência dos alunos, ao representarem as regras escolares, em expressarem, primeiro, os seus objetos, aquilo que está ligado à operacionalização dessas questões no cotidiano escolar. Já a palavra "respeito" tem a ver com os valores circulantes, os aspectos normativos relativos às regras escolares e o sentimento de obrigatoriedade moral (PIAGET, 1994).

As regras do uso do celular e do uniforme são regras convencionais. Já a regra relacionada ao respeito se caracteriza como uma regra moral, uma vez que os alunos reconhecem o seu princípio e destacam a sua universalidade. Os alunos investigados "[...] colocam no mesmo patamar regras convencionais e regras morais como se fosse a mesma coisa" (TOGNETTA; VINHA, 2007, p. 21). Destacamos que, por vezes, essas questões possam estar sendo construídas e/ou priorizadas de forma equivocada pelas escolas investigadas.

O "celular" foi citado 198 vezes. Ao verificarmos as justificativas apresentadas a esse elemento, quando listado em primeiro lugar, vimos que os alunos representam o uso do celular na escola a partir de uma ambivalência. De um lado, têm-se os alunos que consideram essa regra válida e necessária, justificando que a utilização do celular tira a concentração em sala e atrapalha o aprendizado: "É proibido utilizar o celular porque ele atrapalha a aula" (Sujeito_296 Escola_D); "[...] é um eletrônico que jamais poderia ser utilizado na sala, porque ele tira a atenção e não nos deixa prestar atenção nas aulas e assim não nos dedicamos ao estudo" (Sujeito_88 Escola_B). De outro lado, há alunos que avaliam negativamente essa regra e a consideram sem sentido, pois o celular poderia ser empregado como uma ferramenta auxiliar no processo de aprendizagem: "Acho ruim não poder usar o celular porque ele poderia ser utilizado em favor do nosso aprendizado. Poderíamos aprender mais o utilizando de maneira correta" (Sujeito_339 Escola_D); "O celularpoderia ser utilizado como uma ferramenta para o estudo na sala de aula" (Sujeito_175 Escola_B).

Da mesma forma, nas justificativas relacionadas ao "uniforme", evocado 178 vezes, também há uma ambiguidade. Por um lado, estão os alunos que consideram importante a sua utilização, justificando que ele auxilia na identificação do aluno: "O uso do uniforme é para que todos fiquem iguais e é importante para que sejam identificados dentro e fora da escola” (Sujeito_264 Escola_D); “ “...] caso aconteça um acidente, estando uniformizado os alunos são identificados com mais facilidade" (Sujeito_245 Escola_C). Por outro lado, há um reclame entre os alunos questionando o princípio dessa regra: "Aqui na escola não épermitido vir sem o uniforme, mas ai eu pergunto: qual é o problema virmos sem o uniforme?" (Sujeito_336 Escola_D). Para Piaget (1994), esse questionamento e, por vezes, essa ambiguidade tem a ver com a idade dos alunos. Nessa faixa etária, o igualitarismo cede espaço para a equidade que leva em conta cada caso em particular, ou seja, os alunos não mais concebem as regras como iguais para todos, mas passam a considerar as circunstâncias em cada caso. Dessa maneira, ao representarem as regras relacionadas ao uso do celular e do uniforme, em determinados momentos são favoráveis e em outros são desfavoráveis, considerando todas as hipóteses. Para Gouveia et al. (2011), essa ambiguidade está relacionada aos valores de experimentação, os quais são mais abertos à mudança.

Já o "respeito", o qual aparece como um terceiro elemento no núcleo central, citado 122 vezes pelos alunos, se constitui como o único valor que entrou na composição do núcleo central. Para Piaget (1994), o respeito constitui um sentimento importante para a aquisição das noções

Práxis Educativa, Ponta Grossa, v. 16, e2119600, p. 1-19, 2021 Disponível em: < https://www.revistas2.uepg.br/index.php/praxiseducativa $>$ 
morais. Assim, podemos diferenciar dois tipos de respeito: diante das regras e para com o outro, seja ele emissor ou não da ordem. Do respeito deriva a combinação dos sentimentos de amor e de temor. Dessa forma, o temor está na base do respeito unilateral, e, portanto, do desenvolvimento moral heterônomo, e o amor está na base do respeito mútuo, do desenvolvimento moral em direção à autonomia. Nas justificativas dos alunos, há um consenso acerca da necessidade de respeitar-se o emissor das regras: os professores, os funcionários e os colegas da escola para que se tenha um bom convívio. Então, o respeito assume, também, caráter normativo, mesmo que essa representação social não reflita o que, normalmente, acontece na prática das escolas: "Respeitar os professores e funcionários é fundamental porque os professores estão aqui para ensinar e não educar. Já os funcionários devemos respeitar porque são pessoas que cuidam da gente" (Sujeito_326 Escola_D); "O respeito vem em primeiro lugar porque aqui na escola tem muito desrespeito entre os alunos e com os professores. Eu gosto daqui, mas se pudesse melhorar algo seria o respeito" (Sujeito_338 Escola_D); “[...] é necessário respeitar os professores, os colegas e as tias; isso é muito importante para a nossa convivência" (Sujeito_350 Escola_D).

No segundo quadrante, com uma forte tendência à centralidade, aparecem as palavras "proibição" e "boné", que expressam, novamente, o caráter normativo e funcional das regras, respectivamente. "Proibição" caracteriza-se como um desdobramento das regras e está relacionada ao impedimento de determinados comportamentos e objetos no âmbito escolar. "Boné", por sua vez, anuncia um intenso reclame e questionamento dos alunos frente ao impedimento da sua utilização. No terceiro quadrante, há um predomínio de atitudes frente às regras. Há atitudes positivas ("boas", "importantes" e "necessárias") e negativas ("desnecessárias", "ruins" e "rígidas"), as quais estão acompanhadas do contravalor "desrespeito". Por fim, no quarto quadrante, no qual se localiza a periferia, novamente há atitudes de negação, visto que as regras são representadas como "chatas" e "sem sentido". Ambas têm relação com a forma heterônoma com que, muitas vezes, as regras são construídas nas escolas. Ao mesmo tempo, apareceram os objetos "fone de ouvido" e "horário", e ainda os desdobramentos "cuidado com a escola" e o "permanecer em sala".

Tendo em vista que o sistema periférico se constitui como a parte operante da representação social e que a sua importância está relacionada ao funcionamento e à dinâmica das representações sociais, há de considerarmos que o trabalho com as regras escolares precisa partir desses elementos, e, em especial, da discussão com os alunos acerca dos princípios, dos sentidos e dos significados das regras de forma coletiva e democrática. Aliado a isso, e dentre os papéis do sistema periférico, está o de prescrição. Os seus elementos funcionam como uma grade de leitura e, assim, servem de norte para as tomadas de posição. De tal modo, se os alunos consideram as regras chatas e sem sentido, dificilmente eles irão respeitá-las e segui-las no cotidiano escolar. Muitos dos problemas morais presentes nas escolas são decorrentes da falta de adesão dos alunos às regras escolares, que se constituem como receitas prontas, desprovidas de seus princípios. Talvez esteja aí o ponto de partida para o estabelecimento de uma educação moral construtiva e dialógica no espaço escolar, por meio da participação ativa dos alunos, da discussão dos princípios que fundamentam as regras, da livre decisão e do respeito mútuo, o que parece estar no sentido contrário daquilo que está sendo pensado e operacionalizado pelas políticas educacionais brasileiras.

Ao considerarmos como base o conjunto de elementos oriundos da análise do software Evoc, fizemos, a partir das características de cada uma das palavras, o agrupamento dos elementos presentes nos quatro quadrantes, o que possibilitou a construção de seis categorias distintas de evocação: 1) Objetos das regras: celular, uniforme, boné, fone de ouvido, horário; 2) Desdobramento das regras: proibição, cuidado escola, permanecer sala; 3) Atitudes favoráveis: boas, importantes, necessárias; 4) Atitudes desfavoráveis: desnecessárias, ruins, rígidas, chatas, sem sentido; 5) Valores: respeito; e 6) Contravalores: desrespeito.

Práxis Educativa, Ponta Grossa, v. 16, e2119600, p. 1-19, 2021 Disponível em: <https://www.revistas2.uepg.br/index.php/praxiseducativa> 
Após a organização das evocações em categorias, foi realizada a distribuição dos diferentes tipos de palavras e suas correspondentes frequências e percentagens em que apareceram nos quatro quadrantes, conforme podemos visualizar na Tabela 4.

Tabela 4 - Distribuição e percentagem dos tipos de palavras em categorias

\begin{tabular}{l|c|c|c|c}
\hline Categorias & Núcleo central & Elementos intermediários & Periferia & Total \\
\hline \multirow{2}{*}{ Objetos das regras } & 2 & 1 & 2 & 5 \\
\cline { 2 - 5 } & $11,11 \%$ & $5,55 \%$ & $11,11 \%$ & $27,77 \%$ \\
\hline \multirow{2}{*}{ Desdobramentos das regras } & 0 & 1 & 2 & 3 \\
\cline { 2 - 5 } & $0 \%$ & $5,55 \%$ & $11,11 \%$ & $16,66 \%$ \\
\hline \multirow{2}{*}{ Atitudes favoráveis } & 0 & 3 & 0 & 3 \\
\cline { 2 - 5 } & $0 \%$ & $16,66 \%$ & $0 \%$ & $16,66 \%$ \\
\hline \multirow{2}{*}{ Atitudes desfavoráveis } & 0 & 3 & 2 & 5 \\
\hline \multirow{2}{*}{ Valores } & $0 \%$ & $16,66 \%$ & $11,11 \%$ & $27,77 \%$ \\
\hline \multirow{2}{*}{ Contravalores } & 1 & 0 & 0 & 1 \\
\hline \multirow{2}{*}{ Total } & $5,55 \%$ & $0 \%$ & $0 \%$ & $5,55 \%$ \\
\cline { 2 - 5 } & $0 \%$ & 1 & 0 & 1 \\
\hline
\end{tabular}

Fonte: Elaborada pelos autores, 2021.

Do total de 18 palavras diferentes que compõem os quatro quadrantes, 16,66\% fazem parte do núcleo central, $50 \%$ referem-se aos elementos intermediários, e 33,33\% compõem a periferia. Os elementos que constituem o núcleo central aparecem em menor número, porém têm uma frequência mais elevada se comparada aos elementos que integram os outros quadrantes.

No que se refere à análise das categorias, as palavras mais evocadas pelos alunos foram os objetos das regras $(27,77 \%)$ e as atitudes desfavoráveis $(27,77 \%)$. Essas duas categorias estão presentes em todos os quadrantes, sendo ausentes somente no segundo núcleo intermediário, no qual aparecem, em igual número, atitudes favoráveis e desfavoráveis frente às regras escolares. A partir desse achado e considerando a afirmação de La Taille (2010) sobre as instituições escolares trabalharem com a educação moral quase sempre a partir da dimensão menos sofisticada que corresponde à regra, podemos questionar até que ponto essas regras e a forma como elas vêm sendo construídas pelas escolas investigadas contribuem para o desenvolvimento da autonomia intelectual e moral dos alunos. Isso porque, para a diminuição das transgressões escolares, elas não colaboram (ANDRADES-MOYA, 2021).

A estrutura das representações sociais dos alunos acerca das regras reduz-se aos objetos "celular", "uniforme" e "boné", ou seja, às regras convencionais, a partir das quais os alunos expressam aspectos funcionais e normativos. Entre os elementos que compõem o núcleo central, destaca-se apenas o "respeito" que se caracteriza como o único valor presente nos quatro quadrantes. Quanto aos elementos que compõem os núcleos intermediários, ficam evidentes atitudes favoráveis e desfavoráveis, e, na periferia, apresentaram-se em igual número atitudes desfavoráveis, objetos e desdobramentos das regras.

A fim de permitir uma melhor visualização dessa estrutura e organização da representação social das regras, realizamos a análise de similitude, com o apoio do software Simi. Essa análise utiliza o conjunto de dados provenientes do software Evoc e possibilita a visualização do gráfico denominado "árvore máxima" (TURA, 1998), apresentado na Figura 1. A árvore mostra, além da organização, o poder de associação entre os elementos que compõem a representação social das regras. As palavras que entram na composição da árvore máxima de similitude podem formar figuras abertas (arestas soltas) ou podem conectar-se formando figuras fechadas (quadrados, 
triângulos, losangos etc.). A força de ligação entre esses elementos é indicada por meio da espessura das arestas (ALVES-MAZZOTTI, 2007). Nos vértices (junções) da árvore, podemos visualizar as palavras, e, nas arestas (intersecções) que as ligam, é possível observarmos a coocorrência das evocações. As palavras que foram evocadas mais vezes apresentaram, entre parênteses, a frequência de evocação. Para ter um intervalo de confiança, adotamos o mínimo de 13 coocorrências $(5 \%$ do total dos informantes).

Figura 1 - Árvore máxima de similitude da representação social das regras

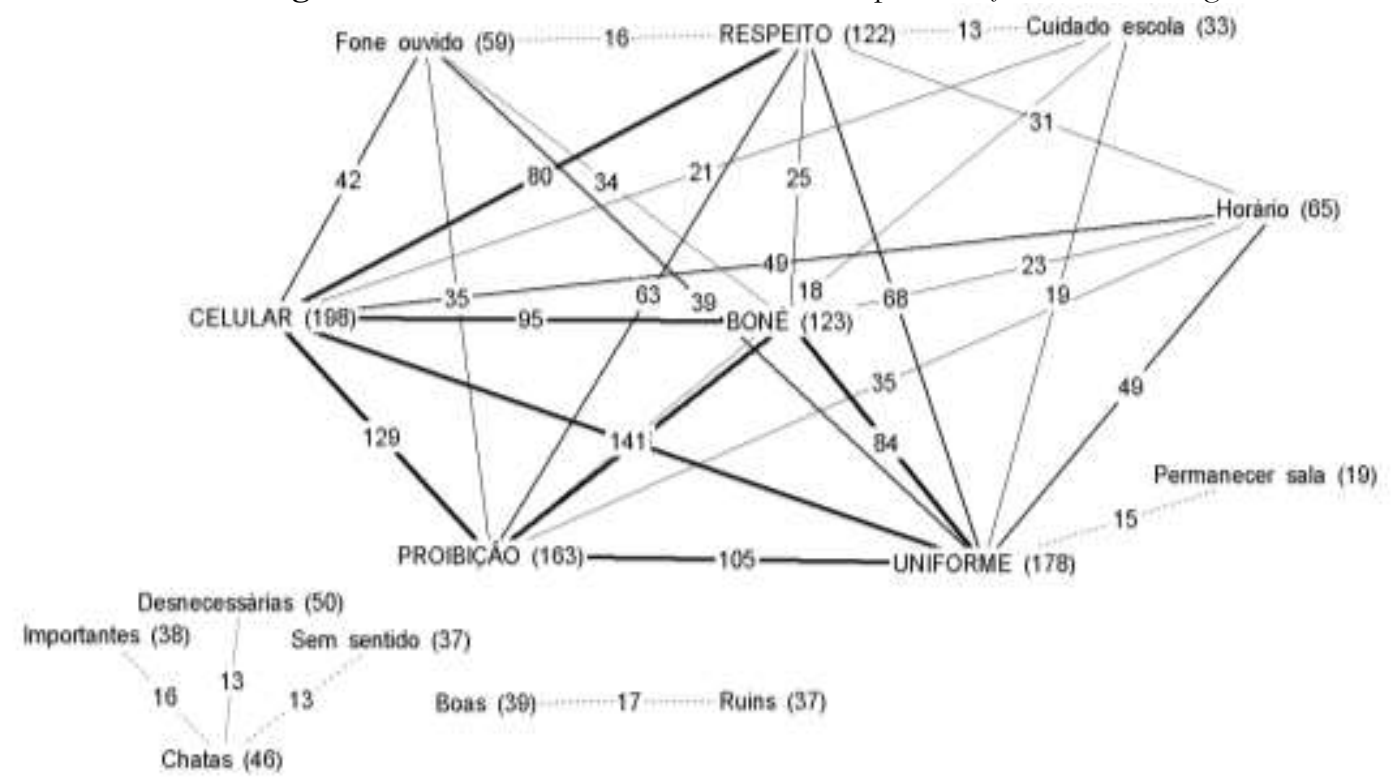

Fonte: Elaborada pelos autores, 2021.

As palavras "celular" e "uniforme" constituem o eixo central com maior frequência de evocações e de coocorrências. Esses elementos são os prováveis termos centrais e organizadores da representação social das regras escolares, uma vez que a palavra "uniforme" possui oito arestas, tendo maior poder associativo que a palavra "celular", que possui sete arestas. Em seguida, tem-se a palavra "boné" com forte tendência à centralidade, a qual foi evocada 123 vezes e possui oito arestas. Além disso, atentamo-nos para o fato de que os objetos das regras ("celular" - "uniforme" - "boné") foram os que apresentaram um maior poder organizativo na representação social das regras escolares, o que corrobora os dados evidenciados nas análises anteriores.

Outrossim, estão desconectadas da árvore máxima as atitudes positivas e negativas frente às regras escolares, as quais apontam para a orientação global, e a tomada de posição dos alunos em relação às regras, aquilo que é discutido pela sociedade em geral e pelos alunos em particular. As atitudes favoráveis/desfavoráveis constituem uma fórmula valorizada pela sociedade na qual os alunos estão inseridos (MOSCOVICI, 2012).

A análise da árvore de similitude aponta para seis atitudes em relação às regras, sendo duas favoráveis ("importantes" e "boas") e quatro desfavoráveis ("chata", "desnecessárias", "sem_sentido" "e "ruins"). A palavra "chatas" associa-se mais a "importantes" do que aos elementos "desnecessárias" e "sem_sentido". Isso indica que os alunos consideram as regras "chatas", e por mais que elas sejam "importantes", muitas delas são consideradas "desnecessárias" e "sem_sentido". Desse modo, há uma prevalência de atitudes negativas frente às regras escolares, as quais, novamente, apontam para a ausência de princípios claros. Vale destacarmos que o importante não são as regras em si, mas o porquê as seguimos, e isso tem a ver com os seus princípios (PIAGET, 1994), uma vez que "[...] o espírito das regras, as matrizes das quais elas 
derivam, assim não se referem ao como agir, mas sim em nome do que agir" (TOGNETTA; VINHA, 2007, p. 33).

Os dados provenientes do software Evoc ainda foram analisados com o apoio do software Complex, comparando-os com os subgrupos de alunos participantes. O intuito foi verificarmos as palavras mais significativas entre os diferentes subgrupos de alunos. Para tanto, comparamos: 1) o gênero masculino com o feminino; 2) os alunos que possuem crença religiosa com aqueles que não possuem; 3) os alunos que possuem fatores de vulnerabilidade social com os que não possuem; 4) os alunos que apresentam fatores de comprometimento da escolarização com os que não apresentam; e 5) os alunos que têm fatores que afetam a conduta escolar com os que não têm. A constituição dos subgrupos foi pensada levando em conta o que circula nos âmbitos social, político e escolar acerca dos fatores que influenciam e determinam as questões relacionadas à moralidade dos alunos. Na Tabela 5, são apresentadas as informações obtidas com o auxílio do software Complex. São consideradas significativas as palavras que tiveram $\mathrm{X}^{2}$ igual ou superior a 3,84 , as quais estão assinaladas em negrito.

Tabela 5 - Palavras evocadas e seus respectivos subgrupos de alunos

\begin{tabular}{|c|c|c|c|c|c|c|c|c|c|c|c|c|c|c|c|}
\hline & \multicolumn{3}{|c|}{ Gênero } & \multicolumn{3}{|c|}{ Crença religiosa } & \multicolumn{3}{|c|}{ Vulnerabilidade } & \multicolumn{3}{|c|}{ Comprometimento } & \multicolumn{3}{|c|}{ Conduta } \\
\hline Evocações & Masc. & Fem. & $\mathrm{X}^{2}$ & Sim & Não & $\mathbf{X}^{2}$ & Sim & Não & $\mathrm{X}^{2}$ & Sim & Não & $\mathrm{X}^{2}$ & Sim & Não & $\mathbf{X}^{2}$ \\
\hline Celular & 91 & 107 & 0,14 & 156 & 42 & 0,31 & 65 & 135 & 0,84 & 158 & 40 & 0,26 & 133 & 65 & 0,75 \\
\hline Respeito & 47 & 75 & 2,26 & 98 & 24 & 0,01 & 37 & 85 & 0,01 & 91 & 31 & 0,77 & 68 & 54 & 3,7 \\
\hline Uniforme & 78 & 100 & 0,01 & - & - & - & 58 & 120 & 0,77 & 148 & 30 & 2,61 & 123 & 55 & 1,9 \\
\hline Boné & 74 & 49 & 12,67 & 101 & 22 & 0,13 & 36 & 87 & 0 & 102 & 21 & 1,49 & 88 & 35 & 2,83 \\
\hline Proibição & 80 & 83 & 1,37 & 128 & 35 & 0,32 & 58 & 105 & 2,94 & 134 & 29 & 1,5 & 102 & 61 & 0,13 \\
\hline Boas & 17 & 22 & 0 & 31 & 8 & 0 & 6 & 33 & 3,16 & 28 & 11 & 0,61 & 17 & 22 & 6,47 \\
\hline Desnecessárias & 16 & 34 & 2,75 & 46 & 4 & 3,63 & 14 & 36 & 0,01 & 42 & 8 & 0,71 & 32 & 18 & 0,02 \\
\hline Desrespeito & 6 & 13 & 0,82 & 16 & 3 & 0,01 & 6 & 13 & 0 & 13 & 6 & 0,57 & 10 & 9 & 0,66 \\
\hline Importantes & 12 & 26 & 2,11 & 34 & 4 & 1,46 & 6 & 32 & 2,87 & 23 & 15 & 6,08 & 19 & 19 & 2,8 \\
\hline Necessárias & 4 & 14 & 2,79 & - & - & - & 1 & 17 & 3,92 & 10 & 8 & 4,19 & 8 & 10 & 2,27 \\
\hline Ruins & 17 & 20 & 0 & 24 & 13 & 4,92 & 9 & 28 & 0,26 & 33 & 4 & 2,08 & 15 & 22 & 8,18 \\
\hline Rígidas & 8 & 15 & 0,53 & - & - & - & 6 & 17 & 0,02 & 16 & 7 & 0,56 & 18 & 5 & 1,44 \\
\hline Chatas & 18 & 28 & 0,35 & 32 & 14 & 2,92 & 17 & 29 & 0,93 & 36 & 10 & 0,03 & 34 & 12 & 1.55 \\
\hline Cuidado escola & 18 & 15 & 1,00 & 26 & 7 & 0 & 12 & 21 & 0,47 & 21 & 12 & 3.34 & 26 & 7 & 2,52 \\
\hline Fone ouvido & 30 & 29 & 0,76 & 45 & 14 & 0,44 & 14 & 45 & 0,71 & 48 & 11 & 0,2 & 46 & 13 & 4,48 \\
\hline Horário & 28 & 37 & 0,01 & 51 & 14 & 0,07 & 18 & 47 & 0,03 & 57 & 8 & 3,05 & 45 & 20 & 0,55 \\
\hline
\end{tabular}

Fonte: Elaborada pelos autores, 2021.

Legenda: Masc. $=$ Masculino; Fem. $=$ Feminino.

$\mathrm{Na}$ primeira coluna da Tabela 5, os elementos "celular", "uniforme" e "respeito" não tiveram contribuição específica de nenhum subgrupo de alunos, assim como as palavras "proibição", "desnecessárias", "desrespeito", "rígidas", "chatas", "cuidado escola”, "horário", "permanecer sala" e "sem_sentido". Isso mostra que esses elementos foram comuns a todos os alunos participantes da pesquisa. Já as palavras "boné", "boas", "importantes", "necessárias", "ruins" e "fone de ouvido" tiveram a contribuição diferenciada de determinados subgrupos de alunos.

"Boné", que evidencia um objeto das regras, foi mais citado pelos alunos do gênero masculino. Já a palavra "boas", que expressa uma atitude positiva frente às regras, teve uma maior contribuição de alunos que não apresentavam fatores que afetam a conduta escolar, que nunca brigaram na escola e que nunca foram encaminhados para a sala da pedagoga. Os alunos que ao representarem as regras escolares como "importantes" são os que apresentam fatores que comprometem a escolarização; aqueles que já reprovaram, não têm hábitos de estudo e se 
autoavaliam de forma negativa. Ademais, os alunos que consideram as regras "ruins" são os que têm crença religiosa e os que não possuem fatores que afetam a conduta escolar. Esse dado contrapõe-se à ideia de que a crença religiosa auxilia na educação moral na escola. A presença ou a ausência de crença religiosa não contribui, portanto, para a mudança ou a alteração do núcleo central das representações sociais das regras empregadas nas quatro escolas investigadas; dessa forma, é um elemento de natureza geral e constitui-se como um grupo periférico nas representações sociais das regras como qualquer outro subgrupo.

Por fim, "fone de ouvido" teve uma maior contribuição dos alunos que apresentam fatores que afetam a sua conduta escolar, isto é, alunos que brigaram ou foram encaminhados para a sala da pedagoga. A Tabela 5 também nos possibilita a análise dos diferentes subgrupos de alunos. $\mathrm{O}$ subgrupo que apresenta fatores que comprometem a escolarização e a conduta escolar foram os dois que mais contribuíram de maneira diferenciada na representação social das regras, pois ambos apresentaram dois $\mathrm{X}^{2}$ com valores significativos, o que reitera o evidenciado anteriormente na análise das variáveis compostas. O subgrupo de alunos que apresentam fatores que comprometem a sua escolarização contribuíram com as palavras "importantes" e "necessárias", e o subgrupo de alunos que possuem fatores que afetam a sua conduta escolar contribuíram com as palavras "boas" e "ruins". Esses quatro elementos constituem-se como atitudes frente às regras, entre as quais percebemos uma contradição, uma vez que ora os alunos consideram as regras como importantes, boas e necessárias, ora como ruins.

Outro fato que se destaca é que nenhum dos subgrupos de alunos teve uma contribuição diferenciada entre as palavras que compõem o núcleo central. Isso demonstra que, independentemente do grupo a que pertencem, os alunos, ao representarem as regras escolares, são unânimes em relacioná-las ao uso do uniforme, ao celular e à necessidade do respeito ao emissor dessas regras.

\section{Considerações finais}

Nesta pesquisa, assumimos o propósito de investigar a estrutura das representações sociais de alunos do $9^{\circ}$ ano do Ensino Fundamental acerca das regras escolares. Assim, neste artigo, abordamos um tema presente na educação, retomado com força no âmbito político atual, que traz implicações não só para as escolas, mas para a sociedade como um todo.

A análise dos dados, os quais derivaram da aplicação de questionário para 359 alunos matriculados em quatro escolas estaduais da cidade de Ponta Grossa (PR), evidenciou que as representações sociais dos alunos frente às regras estão centradas no celular, no uniforme e no respeito. Os dois primeiros caracterizam-se como regras convencionais e o último como uma regra moral, o único valor presente nos quatro quadrantes, ainda que tenha um sentido normativo relacionado ao emissor das regras.

Os alunos colocaram, no mesmo nível, regras convencionais e morais, conferindo uma maior centralidade às convencionais. Essa estruturação tem a ver com a forma como as escolas priorizam essas questões (TOGNETTA; VINHA, 2007), fato que revela a ausência de conhecimentos das comunidades escolares em como trabalhar com a educação moral. No contexto em que a proibição do celular passa a ser tão importante quanto o respeito ao professor e ao colega, há de destacarmos as implicações dessa equivalência ao desenvolvimento moral dos alunos. Essas representações sociais não apenas reproduzem, mas produzem e determinam as relações dos indivíduos com o meio, e definem a origem dos estímulos que circulam e provocam as pessoas (MOSCOVICI, 2012). 
Ao representarem os objetos das regras, os alunos expressaram atitudes favoráveis e desfavoráveis, o que evidenciou, de um lado, os aspectos normativos, e, de outro, os aspectos funcionais dessas regras. As atitudes favoráveis dos alunos foram relacionadas à ideologia das regras, àquilo que é permitido socialmente falar sobre elas. Já as atitudes desfavoráveis dos alunos estão mais ligadas à sua operatividade no cotidiano escolar, principalmente com o reclame aos mecanismos de controle. Essa ambivalência não é percebida quando eles falam do respeito. Há um consenso dos alunos diante desse elemento normativo que aponta para a necessidade de respeitar os professores, os funcionários e os colegas para que haja um bom convívio na escola, mesmo que essa concordância não se reflita, totalmente, nas práticas observadas.

Em relação aos diferentes subgrupos de alunos que constituíram a representação social das regras, nenhum deles contribuiu, significativamente, para a alteração da estrutura da representação social. Os alunos que possuem fatores que afetam a sua conduta e o seu comprometimento escolar foram os que mais colaboraram na constituição da representação social das regras. Outrossim, os referentes a gênero, crença religiosa e vulnerabilidade social não apresentaram uma contribuição significativa. Dessa maneira, por mais que a religião seja empregada nas escolas como uma ferramenta de educação moral e de fortalecimento do controle social, e, ainda que no âmbito político ela se articule, em grande medida, à educação moral, a religião constitui-se como um elemento de natureza geral, um subgrupo periférico como qualquer outro. Da mesma forma, a vulnerabilidade social também se estabelece como um subgrupo periférico na constituição das representações sociais das regras, fato que se contrapõe a discursos políticos da atualidade que, em suas entrelinhas, responsabilizam as escolas pelas mazelas da sociedade e criminalizam os mais pobres (ARROYO, 2021).

A análise dos dados evidenciou que a educação moral está presente nas escolas, expressa de forma individualizada, não planejada e centrada em aspectos práticos e funcionais. Essas características servem de pano de fundo para que, atualmente, o tema seja realocado para fora do âmbito escolar e acadêmico, discutido por detentores de saber técnico, sob um disfarce de nova política, que traz o velho discurso expresso em regras rígidas e inquestionáveis, em normas disciplinares e de conduta, nas quais a hierarquia e a obediência constituem a lógica da organização.

Nessa perspectiva, o foco não deveria estar na instituição de políticas de resgate dos valores morais supostamente perdidos pela sociedade, bem como de naturalização da exclusão de alunos e de professores que não se adaptam a essa lógica de coerção, mas, sim, na construção de políticas e de investimento em todas as escolas públicas, no fomento à formação inicial e continuada dos professores e na valorização das condições do trabalho docente. Assim sendo, a comunidade escolar estaria preparada e segura para construir e encaminhar propostas efetivas de trabalho com a moralidade no cotidiano escolar, de forma cooperativa, participativa e democrática.

\section{Referências}

ABRIC, J. C. A zona muda das representações sociais. In: OLIVEIRA, D. C. de; CAMPOS, P. H. F. (org.). Representações sociais: uma teoria sem fronteiras. Rio de Janeiro: Museu da República, 2005. p. 23-34.

ABRIC, J. C. Les representations sociales: aspects théoriques. In: ABRIC, J. C. (ed.). Pratiques sociales et représentations. Paris: Presses Universitaires de France, 1994. p. 11-35.

ABRIC, J. C. O estudo experimental das representações sociais. In: JODELET, D. (org.). As representações sociais. Rio de Janeiro: EDUERJ, 2001, p. 155-717. 
ABRIC. J. C. Abordagem estrutural das representações sociais: desenvolvimentos recentes. Tradução P. H. F. Campos. In: CAMPOS, P. H. F.; LOUREIRO, M. C. S. (org.). Representações sociais e práticas educativas. Goiânia: UCG, 2003. p. 37-57.

ALVES-MAZZOTTI, A. J. Representações da identidade docente: uma contribuição para a formulação de políticas. Ensaio: Avaliação Políticas Públicas Educação, Rio de Janeiro, v. 15, n. 57, p. 579-594, out./dez. 2007. DOI: https://doi.org/10.1590/S0104-40362007000400008

AMARAL, D. P. do; CASTRO, M. M. de. Educação moral e cívica: a retomada da obrigatoriedade pela agenda conservadora. Cadernos de Pesquisa, São Paulo, v. 50, n. 178, p. 1078-1096, out./dez. 2020. DOI: https://doi.org/10.1590/198053147129

ANDRADES-MOYA, J. Percepción de estudiantes y profesores jefes sobre la eficacia de sanciones formativas: estudio de caso. Revista Brasileira de Educação, Rio de Janeiro, v. 26, p. 1-23, 2021. DOI: $\underline{\text { https://doi.org/10.1590/s1413-24782021260008 }}$

ARAÚJO, U. F. Escola, democracia e a construção de personalidades morais. Educação e Pesquisa, São Paulo, v. 26, n. 2, p. 91-107, jul./dez. 2000. DOI: https://doi.org/10.1590/S1517$\underline{97022000000200007}$

ARROYO, M. Escolas militarizadas criminalizam infâncias populares. [Entrevista cedida a] Ana Luiza Basilio. Carta Capital, São Paulo, 12 set. 2019. Disponível em: https://www.cartacapital.com.br/educacao/miguel-arroyo-escolas-militarizadas-criminalizaminfancias-populares/. Acesso em: 11 nov. 2021.

BARDIN, L. Análise de conteúdo. Tradução Augusto Pinheiro e Luís Antero Reto. 3. ed. Lisboa: Edições 70, 2004.

BAUMAN, Z. O mal-estar da pós-modernidade. Rio de Janeiro: Zahar, 1998.

BRASIL. Decreto $\mathbf{N}^{\mathbf{9}} \mathbf{9 . 6 6 5}$, de 2 de janeiro de 2019. Aprova a Estrutura Regimental e o Quadro Demonstrativo dos Cargos em Comissão e das Funções de Confiança do Ministério da Educação, remaneja cargos em comissão e funções de confiança e transforma cargos em comissão do GrupoDireção e Assessoramento Superiores - DAS e Funções Comissionadas do Poder Executivo FCPE. Brasília: Presidência da República, Secretaria-Geral, Subchefia para Assuntos Jurídicos, [2019]. Disponível em: http://www.Planalto.Gov.Br/Ccivil_03/_Ato20192022/2019/Decreto/D9665.Htm. Acesso em: 17 nov. 2021.

BRASIL. Lei $\mathbf{N}^{\circ}$ 8.663, de 14 de junho de 1993. Revoga o Decreto-Lei no 869, de 12 de dezembro de 1969, e dá outras providências. Brasília: Presidência da República, Casa Civil, Subchefia para Assuntos Jurídicos, [1993]. Disponível em: http://www.planalto.gov.br/ccivil_03/Leis/1989_1994/L8663.htm. Acesso em: 14 set. 2021.

FANTE, C. Fenômeno Bullying. São José do Rio Preto: Ativa, 2003.

FLAMENT, C. Estrutura e dinâmica das representações sociais. In: JODELET, D. (org.). As representações sociais. Rio de Janeiro: EDURJ, 2001. p. 173-186.

GOERGEN, P. Educação moral: adestramento ou reflexão comunicativa. Educação \& Sociedade, Campinas, v. 22, n. 76, out. 2001. DOI: https://doi.org/10.1590/S0101$\underline{73302001000300009}$ 
GOUVEIA, V. V. et al. Valores Humanos: contribuições e perspectivas teóricas. In: TORRES, C. V.; NEIVA, E. R. (org.). Psicologia Social: principais temas e vertentes. Porto Alegre: Artmed, 2011. p. 296-313.

JANCZURA, R. Risco ou vulnerabilidade social? Textos \& Contextos, Porto Alegre, v. 11, n. 2, p. 301-308, ago./dez. 2012.

JARES, X. Educar para a verdade e para a esperança: em tempos de globalização, guerra preventiva e terrorismo. Porto Alegre: Artmed, 2005.

JODELET, D. Imbricações entre representações sociais e intervenção. In: MOREIRA, A. S. P.; CAMARGO, B. V. (org.). Contribuições para a teoria e o método de estudo das representações sociais. João Pessoa: Editora Universitária da UFPB, 2007. p. 45-74.

JOVCHELOVITCH, S. Vivendo a vida com os outros: intersubjetividade, espaço público e Representações sociais. In: GUARESCHI, P.; JOVCHELOVITCH, S. (org.). Textos em representações sociais. 5. ed. Petrópolis: Vozes, 1999. p. 63-85.

KOGA, V. T. O estudo nas representações sociais dos alunos concluintes do ensino fundamental. 2012. Dissertação (Mestrado em Educação) - Universidade Estadual de Ponta Grossa, Ponta Grossa, 2012.

KOGA, V. T.; ROSSO, A. J. Análise da produção científica acerca da educação moral na escola. Psicologia da Educação, São Paulo, n. 43, p. 47-57, 2016.

KOGA, V. T.; ROSSO, A. J. As representações sociais de alunos do $9^{\circ}$ ano do ensino fundamental acerca das regras presentes em escolas públicas. Revista Educação e Cultura Contemporânea, Rio de Janeiro, v. 17, n. 50, p. 179-206, 2020. DOI: https://doi.org/10.5935/2238-1279.20200083

LA TAILLE, Y. de. Formação ética. Do tédio ao respeito de si. Porto Alegre: Artmed, 2009.

LA TAILLE, Y. de. A escola e os valores: a ação do professor. In: LA TAILLE, Y. de. Indisciplina/disciplina: ética, moral e ação do professor. 3. ed. Porto Alegre: Mediação, 2010. p. 5-21.

LA TAILLE, Y. de; MENIN, M. S. de S. Introdução. In: LA TAILLE, Y; MENIN, M. S. S. (org.). Crise de valores ou valores em crise? Porto Alegre: Artmed, 2009. p. 9-13.

LA TAILLE, Y. de; SOUZA, L. S.; VIZIOLI, L. Ética e educação: uma revisão da literatura educacional de 1990 a 2003. Educação e Pesquisa, São Paulo, v. 30, n. 1, p. 91-108, jan./abr. 2004. DOI: https://doi.org/10.1590/S1517-97022004000100006

LIMA, A. P. O uso da religião como estratégia de educação moral em escolas públicas e privadas de presidente prudente. 2008. Dissertação (Mestrado em Educação) - Universidade Estadual Paulista, Presidente Prudente, 2008.

LOBATO, V. da S.; PLACCO, V. M. N. de S. Concepções de professores sobre questões relacionadas à violência na escola. Psicologia Educacional, São Paulo, n. 24, p. 73-90, jan./jun. 2007.

MACHADO, L. B; ANICETO, R. de A. Núcleo central e periferia das representações sociais de ciclos de aprendizagem entre professores. Ensaio: Avaliação Políticas Públicas Educação, Rio de Janeiro, v. 18, n. 67, p. 345-364, abr./jun. 2010. DOI: https://doi.org/10.1590/S0104$\underline{40362010000200009}$ 
MENIN, M. S. de S. Valores na escola. Educação e Pesquisa, São Paulo, v. 28, n. 1, p. 91-100, jan./jun. 2002. DOI: https://doi.org/10.1590/S1517-97022002000100006

MENIN, M. S. S. Educação moral na escola: subsídios a partir da teoria de Piaget. In: MONTOYA, A. D. (org.). Contribuições da Psicologia para a educação. Campinas: Mercado de Letras, 2007. p. $45-62$.

MENIN, M. S. S.; BATAGLIA, P. U. R.; ZECHI, J. A. M. Projetos bem-sucedidos de educação em valores: relatos de escolas públicas brasileiras. São Paulo: Cortez, 2013.

MOSCOVICI, S. A psicanálise, sua imagem e seu público. Tradução Sonia Fuhrmann. Petrópolis: Vozes, 2012.

PAREDES, E. C. Ser professor. Cuiabá: EdUFMT, 2007.

PARRAT-DAYAN, S. Como enfrentar a indisciplina na escola. Tradução Silvia Beatriz Adoue e Augusto Juncal. São Paulo: Contexto, 2009.

PIAGET, J. O juízo moral na criança. Tradução Elzon Leonardon. São Paulo: Summus, 1994.

RIBEIRO, A. C.; RUBINI, P. S. Do Oiapoque ao Chuí - As escolas civis militarizadas: a experiência no extremo norte do Brasil e o neoconservadorismo da sociedade brasileira. Revista Brasileira de Política e Administração da Educação, Brasília, v. 35, n. 3, p. 745-765, set./dez. 2019. DOI: https://doi.org/10.21573/vol35n32019.95997

ROSSO, A. J.; CAMARGO, B. V. As representações sociais das condições de trabalho que causam desgaste aos professores estaduais paranaenses. Educação Temática Digital, Campinas, v. 13, n. 1, p. 269-289, jul./dez. 2011. DOI: https://doi.org/10.20396/etd.v13i1.1180

SÁ, C. P. de. Núcleo Central das Representações Sociais. Petrópolis: Vozes, 1996.

SANTOS, A. C. B. H. dos; TREVISOL, M. T. C. A escola e o desenvolvimento moral do aluno: concepções, práticas e desafios dos profissionais da educação. Revista de Educação, Campinas, v. 21, n. 1, p. 19-29, jan./abr. 2016. DOI: https://doi.org/10.24220/2318-0870v21n1a2895

SANTOS, E. R. dos; ROSSO, A. J. A indisciplina escolar nas representações sociais de professores paranaenses. Psicologia da Educação, São Paulo, n. 34, p. 127-157, jan./jun. 2012.

SHIMIZU, A. de M.; CORDEIRO, A. P.; MENIN, M. S de S. Ética, preconceito e educação: características das publicações em periódicos nacionais de educação, filosofia e psicologia entre 1970 e 2003. Revista Brasileira de Educação, Rio de Janeiro, v. 11, n. 31, p. 167-202, jan./abr. 2006. DOI: https://doi.org/10.1590/S1413-24782006000100012

SHIMIZU, A. M. et al. A. Representações de educadores de escolas brasileiras a respeito de Educação em valores morais. In: REUNIÃO ANUAL DA ANPED, 33., 2010, Caxambu. Anais [...]. Caxambu: ANPEd, 2010. p. 1-16.

SILVA, H. H.; CASTRO, L. V. de. Formação docente e violência na escola. Psicologia da Educação, São Paulo, n. 26, p. 47-66, jan./jun. 2008.

SOUZA, L. L. de; VASCONCELOS, M. S.; Juízo e ação moral: desafios teóricos em psicologia. Psicologia \& Sociedade, Recife, v. 21, n. 3, p. 343-352, 2009. DOI: https://doi.org/10.1590/S0102-71822009000300007 
SPINK, M. J. A ética na pesquisa social: da perspectiva prescritiva à interanimação dialógica. Revista Semestral da Faculdade de Psicologia, Porto Alegre, v. 31, n. 1, p. 7-22. jan./jul. 2000.

TARDELI, D. D. A. O respeito na sala de aula. Petrópolis: Vozes, 2003.

TOGNETTA, L. R. P. Uma reflexão sobre as regras na escola que pretende formar para a autonomia e superar microviolências. In: TOGNETTA, L. R. P.; LEME, M. I. S.; VICENTIN, V. F. (org.). Quando os conflitos nos pertencem: uma reflexão sobre as regras e a intervenção aos conflitos na escola que pretende formar para a autonomia. Campinas: Mercado de Letras, 2013. p. 56-72.

TOGNETTA, L. R. P.; VINHA, T. P. Quando a escola é democrática: um olhar sobre a prática das regras e assembleias na escola. Campinas: Mercado de Letras, 2007.

TREVISOL, M. T. C. Tecendo os sentidos atribuídos por professores do ensino fundamental ao médio profissionalizante sobre a construção de valores na escola. In: LA TAILLE, Y, de; MENIN, M. S. de S. (org.). Crise de valores ou Valores em crise?. Porto Alegre: Artmed, 2009. p. 152184.

TURA, L. F. Aids e estudantes: a estrutura das representações sociais. In: JODELET, D.; MADEIRA, M. C. (org.). Aids e representações sociais: à busca de sentidos. Natal: EDUFRN, 1998. p. 121-154.

VÁSQUEZ, A. S. Ética. 14. ed. Rio de Janeiro: Civilização Brasileira, 2002.

VINHA, T. P. O educador e a moralidade infantil numa visão construtivista. Campinas: Mercado de Letras, 2000.

Recebido em 20/09/2021

Versão corrigida recebida em 15/11/2021

Aceito em 16/11/2021

Publicado online em 23/11/2021 